\title{
Synthesis of $\mathrm{LiNbO}_{3}$ nanoparticles in a mesoporous matrix
}

Anett Grigas and Stefan Kaskel ${ }^{*}$

\section{Full Research Paper}

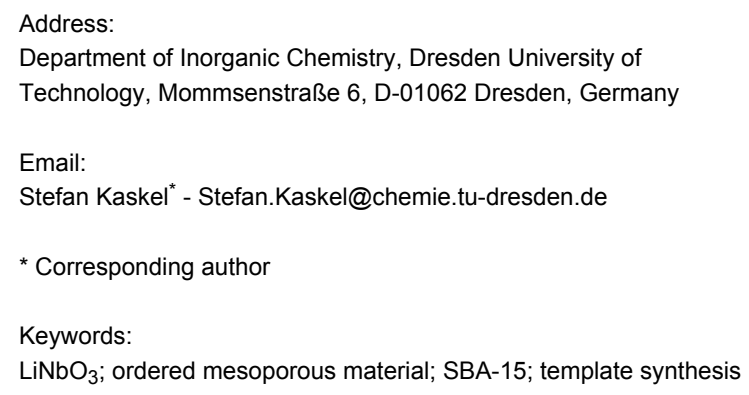

\author{
Beilstein J. Nanotechnol. 2011, 2, 28-33. \\ doi:10.3762/bjnano.2.3 \\ Received: 21 October 2010 \\ Accepted: 23 December 2010 \\ Published: 10 January 2011 \\ Associate Editor: J. J. Schneider \\ (C) 2011 Grigas and Kaskel; licensee Beilstein-Institut. \\ License and terms: see end of document.
}

\begin{abstract}
The synthesis of $\mathrm{LiNbO}_{3}$ nanoparticles in SBA-15 is reported for the first time. The preparation of nanoparticles was carried out by impregnation from the metal precursor and mesoporous silica SBA-15 as the template. A rapid one-step treatment in an IR furnace reduces the preparation time to only $10 \mathrm{~min}$. In comparison, a conventional furnace requires $5 \mathrm{~h}$ reaction time to produce nanoparticles with similar textural properties. Another advantage of applying an IR furnace compared to conventional heating is the extremely high heating rate (up to $10{ }^{\circ} \mathrm{C} / \mathrm{s}$ ) and corresponding time saving. The resulting samples were investigated by powder $\mathrm{X}$-ray diffraction, nitrogen physisorption, and high resolution transmission electron microscopy (HRTEM). The obtained nanoparticles are spherical with a diameter of approximately $10 \mathrm{~nm}$.
\end{abstract}

\section{Introduction}

Lithium niobate is one of the most important ferroelectric materials. At room temperature it has a rhombohedral symmetry and space group $R 3 c$ [1]. It is well known that $\mathrm{LiNbO}_{3}$ has excellent piezoelectrical, pyroelectrical, electro-optical and nonlinear optical properties $[2,3]$. As a result, there are many valuable applications, for example, in integrated optics or surface acoustic wave devices [4,5].

In the past decade, several methods for the synthesis of $\mathrm{LiNbO}_{3}$ have been investigated such as the Czochralski method [6,7], the sol-gel route [8-11], and hydrothermal treatment [12-14].
Of all these synthetic approaches, only the hydrothermal treatment is suited for the preparation of nanosized particles due to the mild reaction conditions involved [15]. Another ingenious route to generate nanoparticles is the use of porous template materials via impregnation techniques, where the oxide is obtained by calcination of suitable precursor solutions with simultaneously removal of the carbon matrix [16-18].

In the present work, we investigated a rapid and efficient onestep route for the direct IR-accelerated synthesis of $\mathrm{LiNbO}_{3}$ nanopowders using an ordered mesoporous silica SBA-15 as the 
template, in combination with an IR furnace for the crystallization. The matrix stabilizes the nanoparticles against sintering while the heat treatment promotes crystallization. For material tailoring purposes the factors influencing the particle size under the reaction conditions on the size of the nanoparticles were considered. The IR furnace uses a lamp for indirect heat treatment and the wavelength can be tuned with the choice of the lamp. In the focal line of a gold plated cylinder with an elliptic profile, resides an IR radiator focusing the radiation in the second focal line where the sample is located inside a quartz tube flow reactor. Temperature measurement and control is carried out via a NiCr-Ni thermocouple located close to the sample.

\section{Results and Discussion}

In general for the preparation of $\mathrm{LiNbO}_{3}, \mathrm{SBA}-15$ was impregnated with a solution containing $\mathrm{LiNO}_{3}$ and $\mathrm{NH}_{4} \mathrm{NbO}\left(\mathrm{C}_{2} \mathrm{O}_{4}\right)_{2} \cdot x \mathrm{H}_{2} \mathrm{O}$. Crystallization was carried out in air using an IR furnace IRF 10 (Behr) in the temperature range
$750-1000{ }^{\circ} \mathrm{C}$ (see Experimental section). LiOH solution was used to remove the SBA-15 matrix and the isolated product was air-dried.

The X-ray powder diffraction (XRD) patterns of the as-prepared samples were dependent on the reaction temperature, heating rate and reaction time, and showed only the reflection peaks of the hexagonal $\mathrm{LiNbO}_{3}$ structure (ICSD 20-631) (Figure 1A, Figure 1B and Figure 1C). As can be seen in Figure 1A, the start of crystallization can be detected at $850{ }^{\circ} \mathrm{C}$, and at $900{ }^{\circ} \mathrm{C}$ all reflections are observed. The intensity of the reflections increases with increasing temperature which indicates a higher degree of crystallinity. The duration of heating (Figure 1B) and the reaction time (Figure 1C) are not dominant effects on the phase formation of $\mathrm{LiNbO}_{3}$ compared to the reaction temperature, but a reaction time of only $10 \mathrm{~min}$ is necessary. Broad peaks were observed for all samples suggesting that sintering of crystallites in the template was minimized. The determination of particle size, as calculated from the Scherrer equation, leads to a
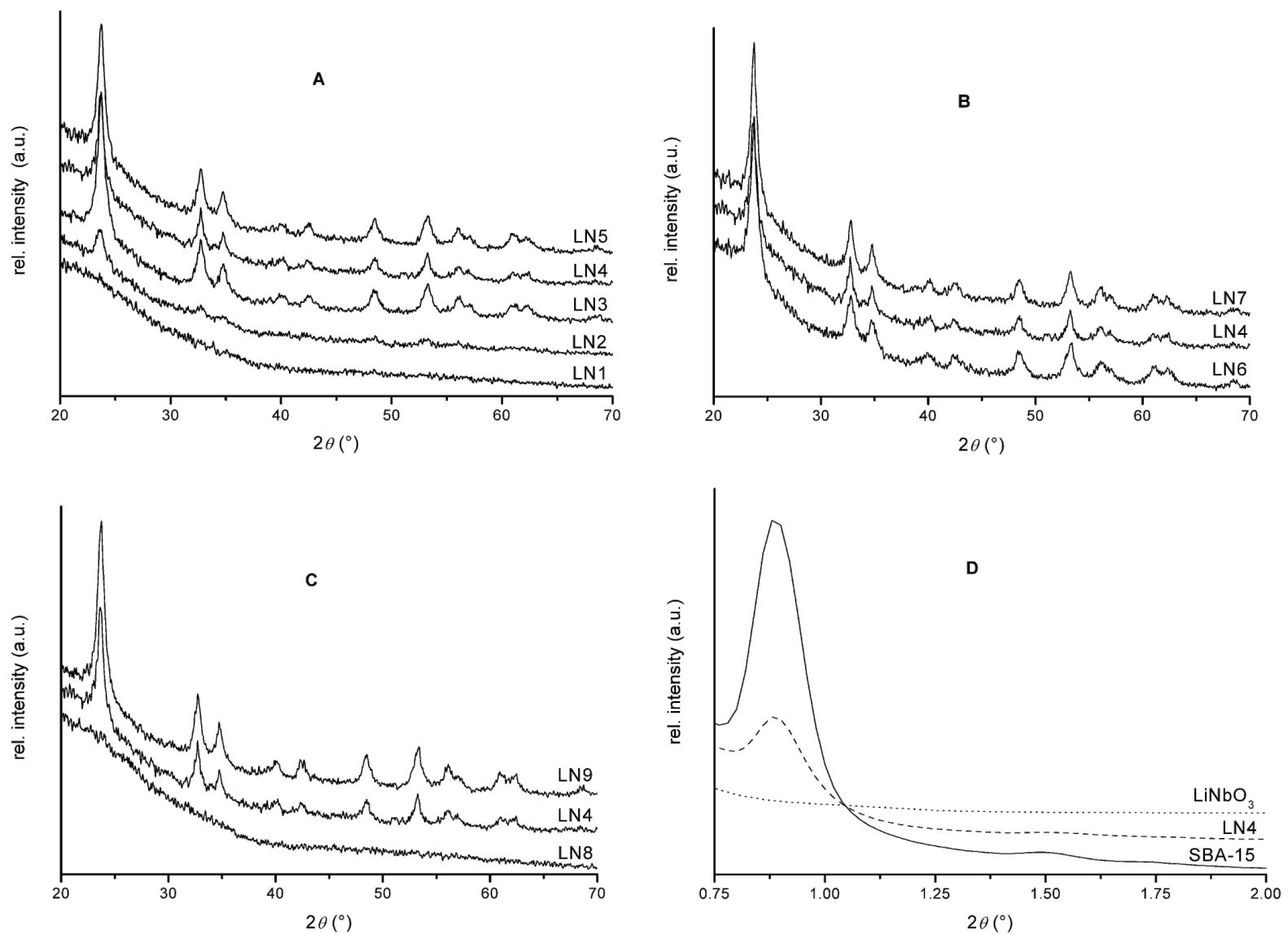

Figure 1: Wide-angle X-ray diffraction patterns of as-prepared $\mathrm{LiNbO}_{3} / \mathrm{SBA}-15$ composites $(\mathrm{LN})$. Effect of reaction temperature (A), heating rate (B), and reaction time $(C)$. Small-angle X-ray diffraction patterns of SBA-15, composite and isolated nanoparticles (D). (For details of the experimental conditions for each sample, see Experimental section.) 
value of about $10 \mathrm{~nm}$ which corresponds well with the pore diameter of the ordered mesoporous silica SBA-15 (10.5 nm in diameter), verifying that the mesoporous silica is a useful template material for the synthesis of particles with a defined size.

Figure 1D shows the small-angle diffraction patterns of SBA$15, \mathrm{LiNbO}_{3}$ composite (LN4) and $\mathrm{LiNbO}_{3}$ nanoparticles after removal of the template. The reflections of SBA-15 correspond to the two-dimensional hexagonal $P 6 \mathrm{~mm}$ symmetry of the well ordered pore system. The XRD pattern of the impregnated material (LN4) shows a single diffraction peak of lower intensity than those of the SBA-15, which indicates that the ordered pore arrangement is not disrupted, even after the incorporation of $\mathrm{LiNbO}_{3}$ nanoparticles. The decrease in intensity is a consequence of the impregnation which reduces the scattering contrast between the silica walls and the empty pores. After removal of SBA-15 with LiOH solution, no peaks can be observed at low angles, which illustrates that the $2 \mathrm{D}$ ordered pore system - as expected - does not remain intact. Elemental analyses of these materials showed that there was no silica residue after the treatment.

Figure 2 shows the nitrogen physisorption isotherms of the SBA-15 and $\mathrm{LiNbO}_{3} / \mathrm{SBA}-15$ composite (LN), and the corresponding pore size distributions of the samples. The measurements were recorded to investigate the effect of incorporation of $\mathrm{LiNbO}_{3}$ on the pore properties of the samples. The data of the specific BET surface areas and pore volumes are listed in Table 1. The textural properties of the unloaded SBA-15 when treated according to the $\mathrm{LiNbO}_{3}$ reaction conditions do not change significantly. For both samples, nitrogen adsorption-desorption curves show type IV isotherms with hysteresis loops, which is typical for mesoporous solids, suggesting that the ordered structure remains intact after $\mathrm{LiNbO}_{3}$ loading. Furthermore, the isotherms show a significant reduction of the specific BET surface area from $729 \mathrm{~m}^{2} \cdot \mathrm{g}^{-1}$ for the SBA-15 to $130-160 \mathrm{~m}^{2} \cdot \mathrm{g}^{-1}$ after impregnation with nanoparticles, as expected. The pore size distribution curves indicate identical pore sizes for both materials, and narrow pore size distributions in the range of $7.0-8.5 \mathrm{~nm}$. These values are typical for the formation of particles inside the pore system and are in accord with the results of small-angle X-ray diffraction.

\begin{tabular}{llll}
$\begin{array}{l}\text { Table 1: Textural characterization of as-prepared } \mathrm{LiNbO}_{3} / \mathrm{SBA}-15 \\
\text { composites }(\mathrm{LN}) \text {. }\end{array}$ \\
Sample & $\begin{array}{l}d_{\text {part }}{ }^{\mathrm{a}} \\
(\mathrm{nm})\end{array}$ & $\begin{array}{l}\mathrm{S}_{\mathrm{g}}^{\mathrm{b}} \\
\left(\mathrm{m}^{2} \cdot \mathrm{g}^{-1}\right)\end{array}$ & $\begin{array}{l}\mathrm{V}_{\mathrm{p}}^{\mathrm{c}} \\
\left(\mathrm{cm}^{3} \cdot \mathrm{g}^{-1}\right)\end{array}$ \\
SBA-15 & - & 729 & 1.38 \\
LN2 & - & 151 & 0.39 \\
LN3 & 9 & 158 & 0.38 \\
LN4 & 10 & 138 & 0.30 \\
LN5 & 12 & 131 & 0.32 \\
LN6 & 10 & 158 & 0.33 \\
LN7 & 11 & 160 & 0.36 \\
LN9 & 10 & 213 & 0.44 \\
\hline
\end{tabular}

aaverage particle diameter estimated from peak broadening; ${ }^{b}$ specific BET surface area; ${ }^{\circ}$ pore volume.

In the TEM images of the composites (Figure $3 \mathrm{~A}$ and Figure $3 \mathrm{~B}$ ), the ordered mesoporous structure of the silica matrix is also observed, and the nanoparticles are detected as black dots. In combination with the results from the XRD analysis, these black points can be interpreted as $\mathrm{LiNbO}_{3}$ nanoparticles. The particles detected as small black points are more or less homogeneously distributed throughout the entire template and the size of the $\mathrm{LiNbO}_{3}$ nanoparticles is compa-
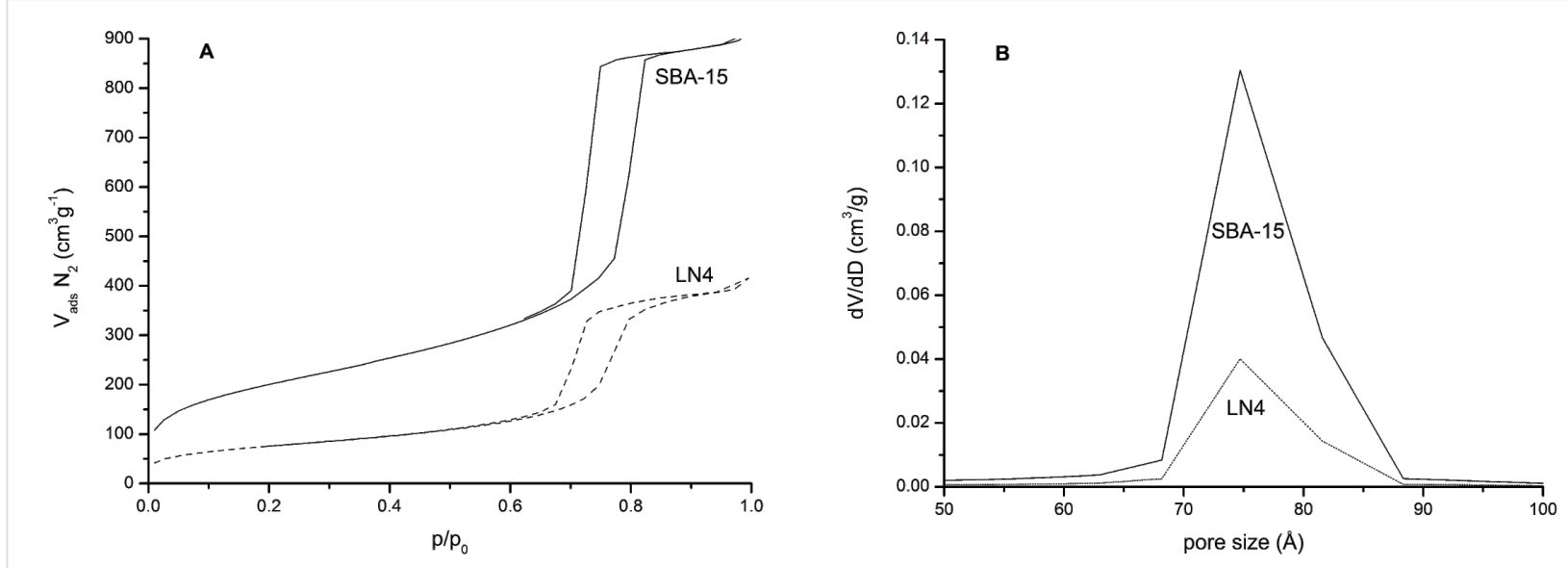

Figure 2: $\mathrm{N}_{2}$ adsorption and desorption isotherms $(77 \mathrm{~K})$ of SBA-15 and as-prepared $\mathrm{LiNbO}_{3} / \mathrm{SBA}-15$ composite $(\mathrm{A})$ and the corresponding pore size distributions of the samples. 
rable to the pore diameter in SBA-15. In Figure 3C the beginning of the template removal after the first treatment with $\mathrm{LiOH}$ solution is demonstrated. The holes in the matrix attest to the collapse of the ordered pore silica structure.

The high resolution TEM images of the nanocrystalline particles (Figure 4) show spherical morphology of one isolated nanoparticle after removal of the silica matrix, and the $d_{012}$ lattice spacing $\left(d_{012}=3.754 \AA\right)$. This value is in agreement with the spacing measured by X-ray powder diffraction. According to the XRD particle size determination (Scherrer equation), no changes are observed for the crystallite size after complete removal of the mesoporous silica. Furthermore, chemical analyses confirm $\mathrm{LiNbO}_{3}$ formation, and a molar ratio of $\mathrm{Li} / \mathrm{Nb} / \mathrm{O}$ of $1 / 1.02 / 2.98$.

\section{Conclusion}

We have presented a template approach for the preparation of nanocrystalline $\mathrm{LiNbO}_{3}$ with grain sizes of $10 \mathrm{~nm}$ by using mesoporous SBA-15 silica as rigid host. The influence of the reaction temperature dominates particle size and crystallization, and a reaction time of $10 \mathrm{~min}$ is only necessary to obtain the phase formation in an IR furnace, while the heating rate has no significant effect. XRD patterns and other characterization results demonstrate crystallinity and phase homogeneity of all as-synthesized samples.

It is expected that the reported method could be extended to prepare other important multi-component oxides, especially ferroelectric materials.

\section{Experimental}

Synthesis of SBA-15 [19]. In a typical preparation, $4 \mathrm{~g}$ of Pluronic P123 was dissolved in $71.8 \mathrm{~g}$ of distilled water and $2.2 \mathrm{~g}$ of concentrated $\mathrm{HCl}(37 \%)$ with stirring for $24 \mathrm{~h}$ at $35^{\circ} \mathrm{C}$. Then, $7.9 \mathrm{~g}$ of TEOS was added and the resulting mixture stirred for $24 \mathrm{~h}$ at $35^{\circ} \mathrm{C}$ and then stored at $130{ }^{\circ} \mathrm{C}$ for $24 \mathrm{~h}$ without stirring. The solid product was recovered, washed with ethanol/ $\mathrm{HCl}$ solution and dried in an oven at $100{ }^{\circ} \mathrm{C}$ for $2 \mathrm{~h}$. Calcination was carried out by slowly increasing the temperature from room temperature to $180^{\circ} \mathrm{C}$ in $3 \mathrm{~h}$, then maintaining the temperature at $180{ }^{\circ} \mathrm{C}$ for $3 \mathrm{~h}$ followed by increasing the temperature from $180^{\circ} \mathrm{C}$ to $550^{\circ} \mathrm{C}$ over $6 \mathrm{~h}$ and finally heating at $550{ }^{\circ} \mathrm{C}$ for $5 \mathrm{~h}$.

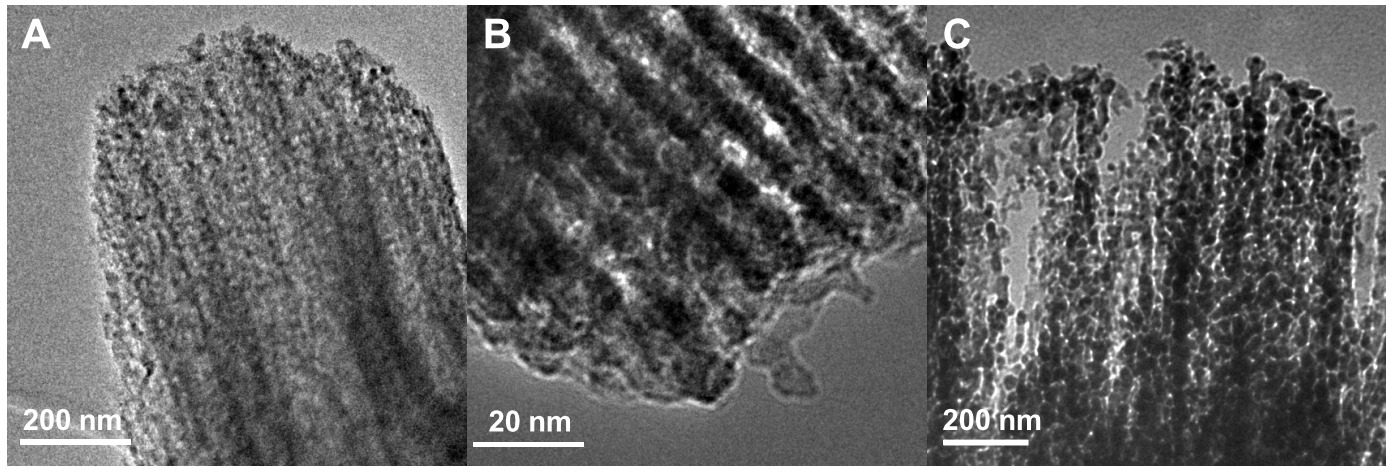

Figure 3: Transmission electron microscope (TEM) images of as-prepared $\mathrm{LiNbO}_{3} / \mathrm{SBA}-15$ composite (A, B), and after the first treatment with $\mathrm{LiOH}$ solution (C).

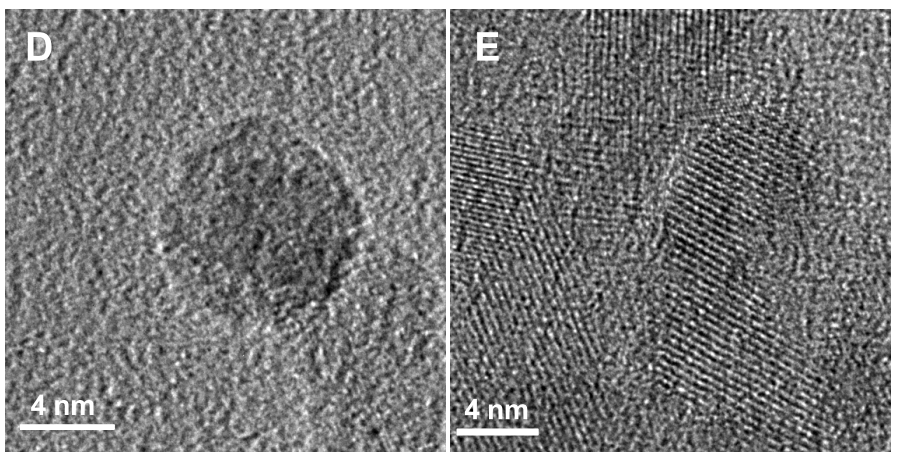

Figure 4: High resolution transmission electron microscope images of $\mathrm{LiNbO}_{3}$ nanoparticles after template removal. 
Synthesis of $\mathrm{LiNbO}_{3} / \mathrm{SBA}-15$ composite. For the precursor solution, $\mathrm{LiNO}_{3}(0.013 \mathrm{~mol}, 95 \%$, Grüssing $)$ and $\mathrm{NH}_{4} \mathrm{NbO}\left(\mathrm{C}_{2} \mathrm{O}_{4}\right)_{2} \cdot x \mathrm{H}_{2} \mathrm{O}(0.013 \mathrm{~mol}, 99.99 \%$, Aldrich $)$ were mixed in a $1: 1$ molar ratio and added to $7 \mathrm{~g}$ of distilled water. After the mixture was heated for $30 \mathrm{~min}$ at $60^{\circ} \mathrm{C}$, all the solid material had dissolved. $1 \mathrm{~g}$ of the SBA-15 material was impregnated with $3.5 \mathrm{~mL}$ of the aqueous precursor solution by incipient-wetness method. Crystallization was carried out in air using an IR furnace IRF 10 (Behr) with a high heating rate $\left(1-10{ }^{\circ} \mathrm{C} / \mathrm{s}\right)$ to a temperature range of $750-1000{ }^{\circ} \mathrm{C}$ and heating times of between 5-20 min at these temperatures (Table 2). Finally, the calcined samples were suspended in a $2.5 \mathrm{M} \mathrm{LiOH}$ solution five times with stirring for $24 \mathrm{~h}$ to remove the SBA-15 matrix. The solid product was filtered, washed with distilled water until $\mathrm{pH}$-neutral and air-dried at $100{ }^{\circ} \mathrm{C}$.

\begin{tabular}{|c|c|c|c|}
\hline Sample & $\begin{array}{l}\theta^{\mathrm{a}} \\
\left({ }^{\circ} \mathrm{C}\right)\end{array}$ & $\begin{array}{l}r^{b} \\
\left({ }^{\circ} \mathrm{C} / \mathrm{s}\right)\end{array}$ & $\begin{array}{l}t^{c} \\
(\min )\end{array}$ \\
\hline LN1 & 750 & 3 & 10 \\
\hline LN2 & 850 & 3 & 10 \\
\hline LN3 & 900 & 3 & 10 \\
\hline LN4 & 950 & 3 & 10 \\
\hline LN5 & 1000 & 3 & 10 \\
\hline LN6 & 950 & 1 & 10 \\
\hline LN7 & 950 & 10 & 10 \\
\hline LN8 & 950 & 3 & 5 \\
\hline LN9 & 950 & 3 & 20 \\
\hline
\end{tabular}

areaction temperature; bheating rate; ${ }^{c}$ reaction time.

Characterization. Wide-angle X-ray diffraction patterns were taken on a STOE Stadi-P diffractometer in transmission geometry using $\mathrm{Cu} \mathrm{K} \alpha_{1}$ radiation (wavelength $\lambda=0.15405 \mathrm{~nm}$ ). The average crystallite size was calculated from the Scherrer equation (STOE size/strain [20]). Instrumental broadening of reflections was taken into account based on $\mathrm{LaB}_{6}$ reference measurements. Small-angle X-ray diffraction patterns were recorded on a Bruker AXS Nanostar. The nitrogen physisorption isotherms at $77 \mathrm{~K}$ were measured using a Quantachrome Autosorb 1C. The samples were pre-treated at $150^{\circ} \mathrm{C}$ for $3 \mathrm{~h}$ in vacuum $\left(10^{-6}\right.$ bar $)$. The specific surface area was calculated from the BET (Brunauer-Emmet-Teller) equation $\left(p / p_{0}=\right.$ $0.05-0.20)$. The pore volume was determined at relative pressure of $p / p_{0}=0.95$. The pore size distribution was estimated from the desorption branch of the isotherm using Density Functional Theory (DFT). Chemical analyses to determine the content of lithium, and niobium were carried out with an ICPOES Vista (Varian). The samples were digested in hydrofluoric acid with microwave heating at $180^{\circ} \mathrm{C}$ for $20 \mathrm{~min}$. The oxygen content was determined with a TCH-600 (Leco) using the carrier gas hot extraction technique. TEM investigations were carried out with a $200 \mathrm{kV}$-TEM FEI Tecnai F20/Cs-corrected electron microscope at the Triebenberg Laboratory for high resolution TEM and electron holography.

\section{Acknowledgements}

The authors would like to thank Dr. Gudrun Auffermann for support of the elemental analyses at the Max Planck Institute for Chemical Physics of Solids and Dr. Dorin Geiger for TEM micrographs at the Triebenberg Laboratory for HRTEM and Electron Holography.

\section{References}

1. Abrahams, S. C.; Reddy, J. M.; Bernstein, J. L. J. Phys. Chem. Solids 1966, 27, 997-1012. doi:10.1016/0022-3697(66)90072-2

2. Jaeger, N. A. F.; Young, L. J. Lightwave Technol. 1989, 7, 229-235. doi:10.1109/50.17760

3. Lanfredi, S.; Rodrigues, A. C. M. J. Appl. Phys. 1999, 86, 2215-2219. doi:10.1063/1.371033

4. Yim, Y.-S.; Shin, S.-Y. Opt. Commun. 1998, 152, 225-228. doi:10.1016/S0030-4018(98)00198-9

5. Yang, W.-S.; Lee, H.-Y.; Yoon, D.-H. J. Cryst. Growth 2002, 244, 49-52. doi:10.1016/S0022-0248(02)01498-7

6. Nassau, K.; Levinstein, H. J.; Loiacono, G. M. J. Phys. Chem. Solids 1966, 27, 989-996. doi:10.1016/0022-3697(66)90071-0

7. Kasemir, K.; Betzler, K.; Matzas, B.; Tiegel, B.; Wahlbrink, T.; Wöhlecke, M.; Gather, B.; Rubinina, N.; Volk, T. J. Appl. Phys. 1998, 84, 5191-5193. doi:10.1063/1.368769

8. Terabe, K.; Iyi, N.; Kimura, S. J. Mater. Sci. 1995, 30, 1993-1998. doi:10.1007/BF00353024

9. Pitcher, M. W.; He, Y.; Bianconi, P. A. Mater. Chem. Phys. 2005, 90, 57-61. doi:10.1016/j.matchemphys.2004.09.030

10. Zeng, H. C.; Tung, S. K. Chem. Mater. 1996, 8, 2667-2672. doi:10.1021/cm960197n

11. Camargo, E. R.; Kakihana, M. Solid State Ionics 2002, 151, 413-418. doi:10.1016/S0167-2738(02)00547-7

12. An, C.; Tang, K.; Wang, C.; Shen, G.; Jin, Y.; Qian, Y. Mater. Res. Bull. 2002, 37, 1791-1796. doi:10.1016/S0025-5408(02)00869-3

13. Yu, J.; Liu, X. Mater. Lett. 2007, 61, 355-358. doi:10.1016/j.matlet.2006.04.087

14. Niederberger, M.; Pinna, N.; Polleux, J.; Antonietti, M. Angew. Chem. 2004, 116, 2320-2323. doi:10.1002/ange.200353300 Angew. Chem., Int. Ed. 2004, 43, 2270-2273. doi:10.1002/anie. 200353300

15. Feng, S.; Xu, R. Acc. Chem. Res. 2001, 34, 239-247. doi:10.1021/ar0000105

16. Wohlrab, S.; Weiss, M.; Du, H.; Kaskel, S. Chem. Mater. 2006, 18, 4227-4230. doi:10.1021/cm060367o

17. Schwickardi, M.; Johann, T.; Schmidt, W.; Schüth, F. Chem. Mater. 2002, 14, 3913-3919. doi:10.1021/cm0211857

18. Kang, M.; Kim, D.; Yi, S. H.; Han, J. U.; Yie, J. E.; Kim, J. M. Catal. Today 2004, 93-95, 695-699. doi:10.1016/j.cattod.2004.06.063

19. Choi, M.; Heo, W.; Kleitz, F.; Ryoo, R. Chem. Commun. 2003, 1340-1341. doi:10.1039/b303696k

20. Win $X^{P O W}$ size/strain analysis, 1.06; STOE \& Cie GmbH: Darmstadt, 1999. 


\section{License and Terms}

This is an Open Access article under the terms of the Creative Commons Attribution License

(http://creativecommons.org/licenses/by/2.0), which permits unrestricted use, distribution, and reproduction in any medium, provided the original work is properly cited.

The license is subject to the Beilstein Journal of Nanotechnology terms and conditions:

(http://www.beilstein-journals.org/bjnano)

The definitive version of this article is the electronic one which can be found at:

doi:10.3762/bjnano. 2.3 